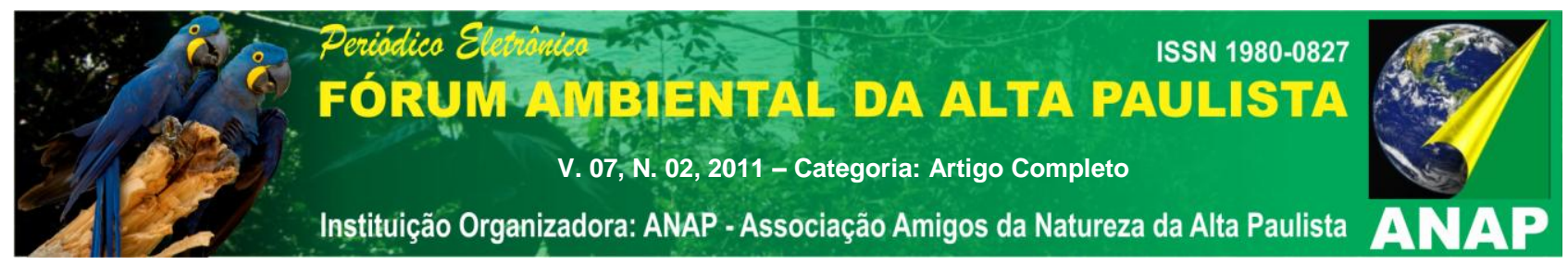

\title{
GERENCIAMENTO DOS RECURSOS HÍDRICOS NO ESTADO DO CEARÁ: PRINCÍPIOS E PRÁTICAS
}

\author{
Cíntia dos Santos Lins ${ }^{1}$
}

RESUMO: Este trabalho tem como objetivo principal analisar os impactos do sistema de gestão das águas do Estado do Ceará, implantado na década de 1990 com o intuito de sanar os problemas associados à escassez hídrica no território cearense, bem como suprir de água a Região Metropolitana de Fortaleza RMF, uma das maiores demandantes de recursos hídricos do Estado. O modelo de gerenciamento foi implantado no Ceará a partir de seis premissas básicas (1. Bacia hidrográfica como unidade de gestão; 2. Gerenciamento integrado, participativo e descentralizado; 3. Reconhecimento da água enquanto valor econômico; 4. Necessidade de instituição da outorga como forma de controle de uso; 5 . Consideração da indissociabilidade quantidade/qualidade; 6 . Necessidade da implantação de órgão específico para gestão da água.) e serviu de base para o sistema adotado nacionalmente (Lei $n^{\circ}$ 9.433). O fato é que, mesmo sendo considerada modelo, a gestão dos recursos hídricos no Estado do Ceará encontra-se baseada na construção de grandes fixos (açudes, barragens e canais) voltados para o incremento do abastecimento de água, mas que trazem grandes impactos socioeconômicos para o Estado, sendo que o principal deles diz respeito a inacessibilidade à água por parte das comunidades atingidas por esse processo. Atualmente 0 principal exemplo da consolidação da política de abastecimento hídrico do Estado do Ceará é o Canal da (Des)Integração que visa abastecer de água as manchas do agrohidronegócio, bem como a área industrial do Estado (RMF). As obras ainda não estão totalmente concluídas, mas seus impactos já podem ser claramente observados.

Palavras-chave: gestão dos recursos hídricos; Ceará; Canal da Integração

\section{INTRODUÇÃO}

A cada dia, o espaço cearense torna-se mais dinâmico e isso é percebido a partir do momento em que o Estado passou a direcionar seus recursos financeiros à instalação de novos sistemas de engenharia associados à eletricidade, aos transportes,

\footnotetext{
${ }^{1}$ Geógrafa, doutoranda em Geografia pela Universidade Estadual Paulista (Unesp-Presidente Prudente). Bolsista do CNPq. Membro do Centro de Estudos de Geografia do Trabalho (CEGeT), coordenado pelo professor Dr. Antonio Thomaz Junior. E-mail: lins0307@gmail.com
} 


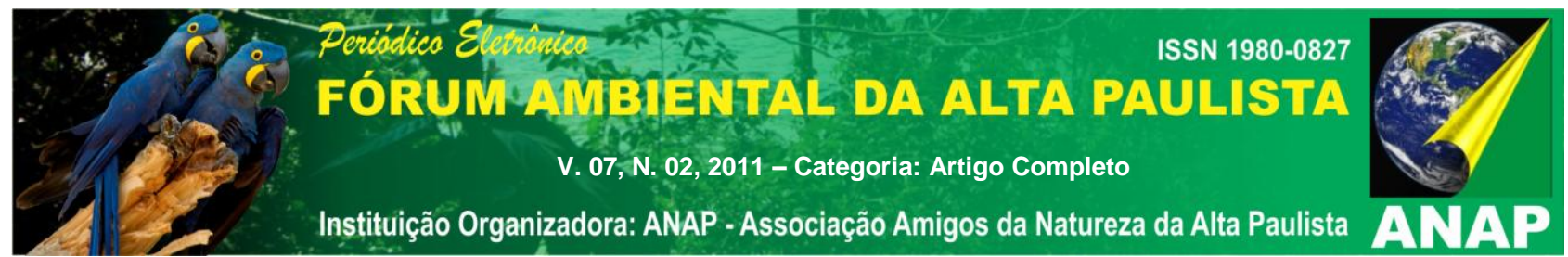

saneamento básico e ao abastecimento de água, por exemplo. Os mencionados investimentos proporcionaram um crescimento cada vez mais acelerado de tal espaço, e podem ser percebidos pelo contínuo processo de modernização da agricultura e da indústria, pela expansão do comércio e pelas formas de apropriação de seus recursos naturais.

Todo esse dinamismo verificado no Estado do Ceará desde meados da década de 1980 é fruto da ideologia capitalista, baseada no estímulo ao consumo de mercadorias e, conseqüentemente, de recursos naturais, entre os quais sobressai a água. A água é um dos elementos naturais mais importantes por estar ligada diretamente à sobrevivência humana e à realização das mais diversas atividades (seja no processo produtivo, seja como componente do produto final) e, no Estado do Ceará, sua escassez relativa foi por muito tempo considerada um empecilho ao desenvolvimento da economia. Diante disto, tal recurso tornou-se um bem gerenciado.

O Trabalho aqui apresentado tem como objetivo analisar os impactos da atual política de gerenciamento dos recursos hídricos, baseada na construção de fixos associados ao abastecimento hídrico de grandes empreendimentos econômicos mas que, muitas vezes, expropria as populações mais carentes e que são diretamente atingidas por tal política.

\section{A IMPLANTAÇÃO DO SISTEMA DE GESTÃO DAS ÁGUAS DO CEARÁ: UMA BREVE CONTEXTUALIZAÇÃO}

Durante muito tempo a escassez hídrica no Estado do Ceará foi justificada apenas por suas condições naturais. Atualmente, porém, com a abertura de mercados implantada no Estado pelo Governo das Mudanças, essa escassez deixa de ser exclusivamente um fator natural para ser, também, de crescente demanda. Isso é possível pelo seguinte motivo: no território cearense passaram a ser desenvolvidas atividades, dentre as quais cita-se a agricultura irrigada e a indústria, dependentes de grandes quantidades de água para sua realização. Como mostra o gráfico 1, a agricultura e a indústria são responsáveis por mais de $85 \%$ da demanda total hídrica do Estado. Essa escassez hídrica decorrente da demanda é tanto causa como conseqüência desse processo de reestruturação socioespacial. O Estado cria estruturas de abastecimento de 


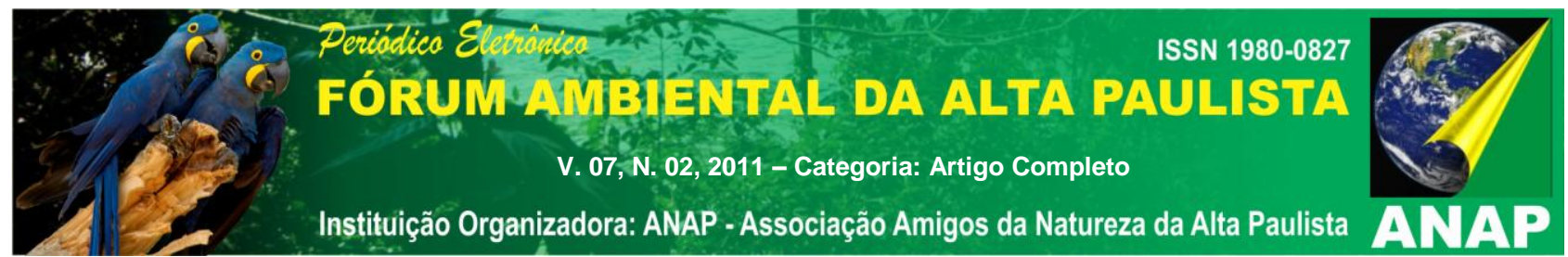

água, consequentemente novos investimentos do capital privado são implantados, gerando cada vez mais demanda e tornando-se necessário o estabelecimento de novas políticas aptas a se encarregarem do gerenciamento das águas cearenses.

Ao se referir ao tema recursos hídricos, Nascimento (2004), em seu artigo intitulado "Os recursos hídricos e o semiárido", comenta que:

Por conta da crescente demanda por água ao consumo humano e para as atividades produtivas, há que se adequar a relação água/sociedade (cada habitante da bacia hidrográfica) ao processo de gerenciamento integrado da água, a qual Rebouças (1997) chamou de disponibilidade hídrica social nos rios porque à proporção que a demanda por água aumenta, alcançando determinados níveis de disponibilidades sociais - disponibilidades per capita - a demanda por gerenciamento é fundamental.

Por décadas o gerenciamento dos recursos hídricos do Estado do Ceará ficou sob a responsabilidade do DNOCS, mas esse gerenciamento se dava de maneira incompleta, sobretudo porque as ações deliberadas por tal instituição eram limitadas à construção de fixos (açudes, barragens e poços artesianos, por exemplo) implantados sem as devidas observações das particularidades locais, sejam elas ambientais ou socioeconômicas. Atualmente o departamento é responsável pela implantação de perímetros irrigados e pela construção de fixos federais associados ao abastecimento de água.

Perímetros irrigados são projetos públicos de irrigação que têm sua infraestrutura projetada, implantada e operacionalizada pelo Estado. Esses perímetros podem ser utilizados de duas formas: exclusivamente para a exploração agrícola familiar ou para a exploração mista (lotes para agricultura familiar e empresarial. Em entrevistas com membros do DNOCS, observa-se que os perímetros irrigados dotados de maior aparato tecnológico são os de economia mista, a exemplo dos Perímetros Irrigados Jaguaribe-Apodi e Tabuleiro de Russas (situados na região Jaguaribana), o que evidencia que o Estado procura das condições para a viabilização do processo de acumulação e reprodução do capital de grande monta. Atualmente o Estado do Ceará conta com 32 Perímetros Irrigados, no total de 40.481ha de terras que demandam aproximadamente $728,658 \mathrm{hm}^{3}$ de água por ano. Dessas terras, 60\% estão em território jaguaribano.

Como parte desse processo de mudanças, tanto a implementação dos perímetros irrigados quanto a gestão dos recursos hídricos do Estado foram 


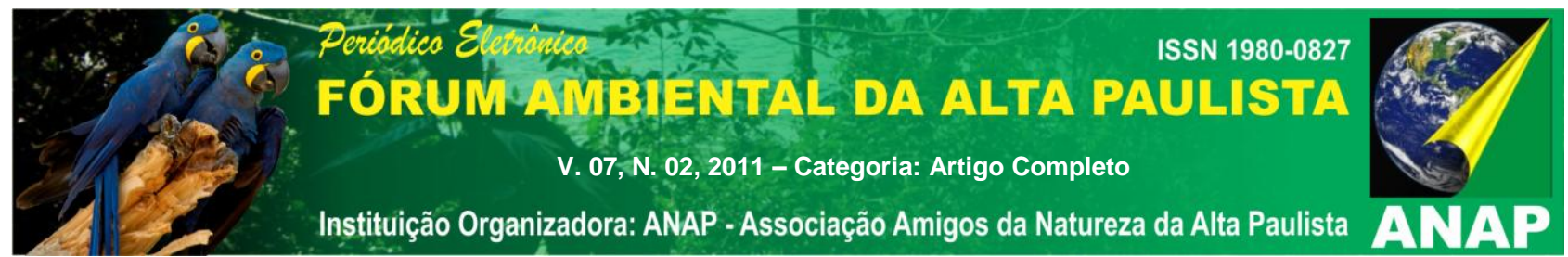

descentralizados do DNOCS, o qual, a partir de então, atua em conjunto com a Secretaria dos Recursos Hídricos, criada no ano de 1987 com o intuito de promover o uso racional e integrado dos recursos hídricos. A SRH também é encarregada de coordenar, gerenciar e operacionalizar estudos, pesquisas, programas, projetos e serviços associados à água, além de promover a articulação entre os órgãos federais (DNOCS e ANA, por exemplo) e municipais que atuam no setor das águas.

Posteriormente foi criada a Sohidra, órgão executor da SRH e do DNOCS (Ceará), responsável pela construção de açudes, barragens, adutoras, poços, entre outros. Nesse mesmo período foi reestruturada a Funceme, com a atribuição de desenvolver pesquisas no campo dos recursos hídricos superficiais e subterrâneos e a prestação de serviços a empresas privadas na área de meteorologia e recursos hídricos.

E para consolidar a gestão dos recursos hídricos no Estado, no ano de 1992 foi estabelecido o Plano Estadual de Recursos Hídricos e instituído o Sistema de Gestão dos Recursos Hídricos (SIGERH) pela Lei Estadual n¹1.996, de 24 de junho do mesmo ano. Em consonância com os princípios da Lei 9.433, que tem a bacia hidrográfica como unidade básica de gestão; o gerenciamento seria integrado, participativo e descentralizado; a água seria reconhecida como bem econômico; a outorga, vista como um instrumento indispensável ao gerenciamento; defendia-se o reconhecimento da indissociabilidade quantidade/qualidade; e, por último, a necessidade da implantação de um órgão que auxiliasse a SRH na gestão das águas (no caso do Ceará, a Cogerh seria esse órgão). Atualmente fazem parte do Sigerh a Funceme, a $\mathrm{SRH}$, a Sohidra e a Cogerh, todas instituições subordinadas à Agência Nacional das Águas (ANA).

Embora instituído em 1992, o Sigerh só foi consolidado em 1993, quando o Estado cria a Cogerh com forte apoio do Banco Mundial ${ }^{2}$, um dos principais agentes financiadores dos programas e projetos associados ao gerenciamento dos recursos hídricos do Ceará e um dos maiores interessados na privatização dos recursos hídricos e na formação de um mercado de águas no Estado. Como instituição encarregada de gerenciar os recursos hídricos de domínio do Estado, a Cogerh atua de acordo com três

\footnotetext{
${ }^{2}$ De acordo com Shiva, 2006, p.107, "[...] O Banco Mundial tem, atualmente, títulos a receber no valor de cerca de vinte bilhões de dólares em projetos de água, dos quais 4,8 bilhões são para água em centros urbanos e saneamento, 1,7 bilhão de dólares para esquemas de água em zonas rurais, 5,4 bilhões de dólares para a irrigação, 1,7 bilhão de dólares para energia elétrica e três bilhões de dólares para projetos ambientais relacionados a questões da água."
} 


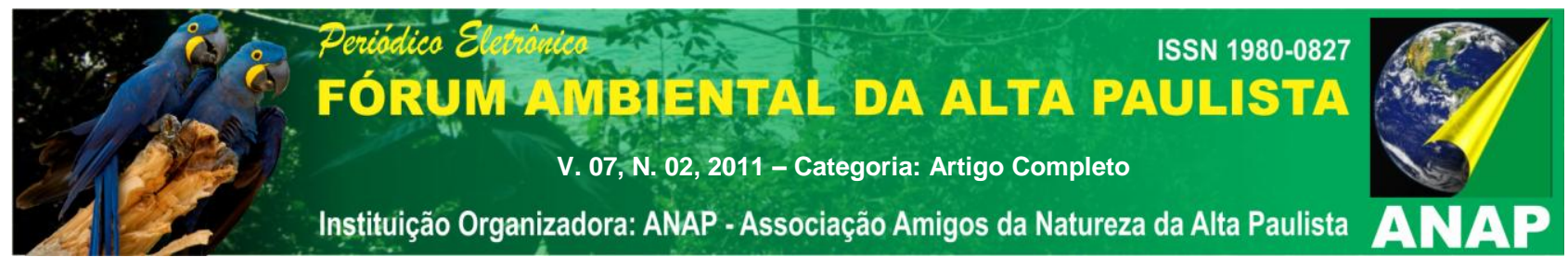

princípios básicos, quais sejam, a integração (com a população e com as instituições encarregadas da gestão), a descentralização (tomada de decisões de forma democrática) e a participação (se daria pela implantação dos Comitês de Bacia, onde se encontram os principais atores envolvidos na gestão: Estado e usuários da água).

O Estado do Ceará foi o pioneiro na criação de uma companhia de gestão das águas e junto com os Estados de São Paulo e Rio Grande do Sul foi o pioneiro, também, na instituição dos Comitês de Bacias Hidrográficas (CBHs). Destes, o primeiro a ser implantado no Ceará foi o $\mathrm{CBH}$ do rio Curu, e, atualmente, das onze sub-bacias hidrográficas existentes no Estado, apenas a do rio Poti (um dos afluentes do rio Parnaíba), não possui comitê por se tratar de uma bacia de domínio da União, e, assim, só pode ser instituído e coordenado pela ANA.

Cabe à Cogerh responder, ainda, por um dos pontos mais polêmicos do gerenciamento dos recursos hídricos como um todo: a outorga e a cobrança pela captação da água bruta. Em trabalhos de campo e entrevistas com membros da Cogerh e dos Comitês de Bacia, observamos que a cobrança pela captação de água está em seus momentos iniciais. É aplicada nas bacias hidrográficas do Acaraú, Metropolitanas e Baixo e Médio Jaguaribe. Na maioria dos casos, os valores cobrados são irrisórios para os grandes produtores, os quais muitas vezes são até isentos do pagamento dessa taxa. Ao mesmo tempo, porém, estes valores chegam a ser exorbitantes para os pequenos produtores, que não têm como se sustentar e concorrer com os demais produtores. Desse modo, eles ficam excluídos do mercado globalizado.

A partir de trabalhos de campo e em entrevistas semi-estruturadas com representantes da Cogerh (Limoeiro do Norte e Fortaleza) e com membros do Comitê de Bacia do Médio Jaguaribe, observamos que os três princípios nos quais a Cogerh se baseia para a execução da gestão dos recursos hídricos do Estado do Ceará são um tanto quanto contraditórios, pois há uma grande distância entre o estabelecido na legislação e o ocorrido na prática.

\section{A CONSOLIDAÇÃO DO GERENCIAMENTO DOS RECURSOS HÍDRICOS CEARENSES: O PROGRAMA ÁGUAS DO CEARÁ}




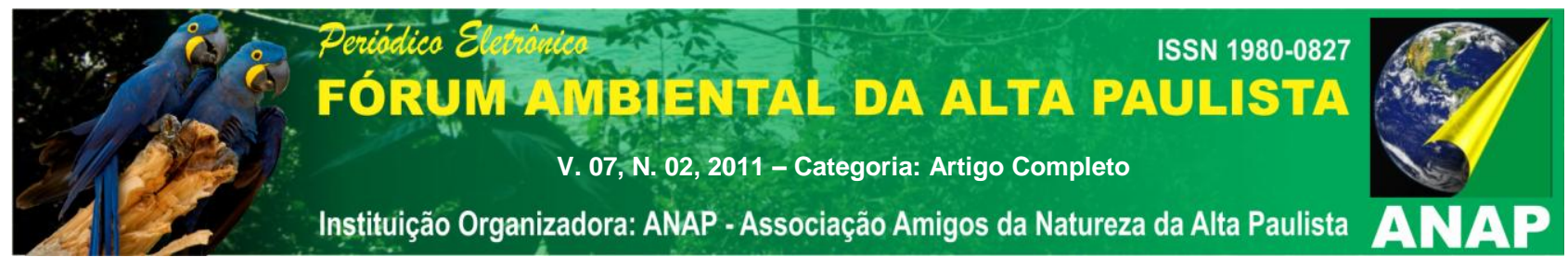

Dentre as medias estruturais e não-estruturais de caráter modernizante implantadas pelo Estado do Ceará no concernente aos recursos hídricos podemos citar o Águas do Ceará, concebido como o maior programa associado ao abastecimento de água da história cearense, se considerarmos o número e a complexidade do sistema de engenharia envolvido.

O Águas do Ceará é o programa piloto do Estado, dotado de subprogramas que atuam diretamente na gestão dos recursos hídricos do Ceará mediante introdução de medidas estruturais e não-estruturais. Este programa conta com o financiamento do Banco Mundial que, como já citado, é um dos principais credores da política de gestão das águas cearenses e um dos mais interessados nos prováveis lucros decorrentes de uma possível e futura privatização da água. Percebe-se que a crescente intervenção do Banco Mundial objetiva uma subversão no controle das reservas hídricas do Estado, e hoje o território cearense funciona como um verdadeiro laboratório dos programas desenvolvidos por tal banco.

De acordo com a SRH (2001), o programa piloto do Águas do Ceará tem como premissas gerais:

1. A garantia da disponibilidade de água do território cearense que permita o abastecimento urbano-industrial e da produção hidroagrícola, através de uma rede de açudes de grandes portes interligada a um conjunto de açudes de médio e grande portes;

2. O sistema de transferência de água baseado em adutoras, canais e perenização de rios;

3. O uso da água subterrânea com o objetivo de substituir as políticas emergenciais no combate às secas.

Essas três premissas são (ou deviam ser) concretizadas nos seus subprogramas, a exemplo do Proágua, desenvolvido no âmbito federal, além do Proásis, Prourb, Progerirh, desenvolvidos no âmbito estadual. Ao observarmos tais programas, concluímos serem eles implantados de maneira territorialmente seletiva, porquanto estão concentrados apenas em pontos estratégicos do Estado, ou seja, aqueles pontos que responderam com maior rapidez às condições impostas pelo modo de produção capitalista e, por conseqüência, socialmente excludentes, por não beneficiar igualmente a população e os pequenos produtores. Shiva (2006, p.107), ao comentar sobre os programas e projetos implantados com o auxílio do Banco Mundial, assim se pronuncia: 


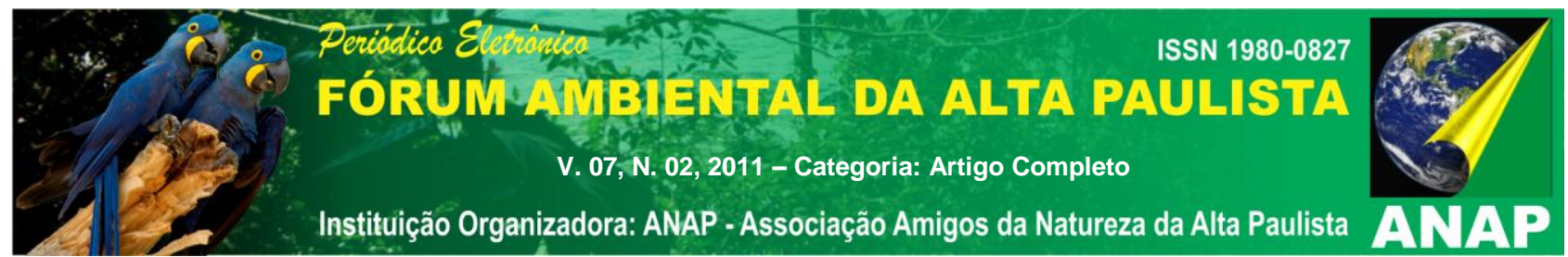

[...] são projetos de águas gigantes, na maioria dos casos, beneficiam os poderosos e despojam os fracos. Até mesmo quando tais projetos são financiados com recursos públicos, seus beneficiários são principalmente construtoras, indústrias e grandes agricultores.

O Progerirh (Programa de Gerenciamento e Integração dos Recursos Hídricos), principal deles, foi criado no ano 2000 e, desde então, tem como meta principal a interligação das bacias hidrográficas do Estado mediante construção de uma rede de açudes de grande porte, entre os quais se destaca o açude Castanhão, e açudes de pequeno e médio portes localizados nos vazios hídricos ou em áreas onde a demanda é crescente. Fruto de uma parceria público-privada (Estado e Banco Mundial), os objetivos deste subprograma giram em torno de seis componentes básicos: a gestão (participativa, por meio da criação dos Comitês de Bacia); o incremento de rede (através da construção de aproximadamente 40 açudes em todo o Estado do Ceará em um período de 12 anos); a recuperação da infra-estrutura hidráulica; o desenvolvimento hidroambiental de microbacias hidrográficas; o projeto piloto para monitoramento dos aqüíferos; e os eixos de integração (SRH, 2002).

A última meta, considerada uma das mais polêmicas por conta dos diversos impactos por ela provocados, é a implantação de eixos de integração de bacia destinados a perenizar rios e transpor os recursos hídricos das regiões com maior potencial e volume hídrico para as regiões com escassez (seja ela natural ou decorrente da crescente demanda), aumentando a área de cobertura do abastecimento humano, agrícola e industrial, mediante a interligação de bacias hidrográficas.

De acordo com o Conselho de Altos Estudos e Assuntos Estratégicos, atualmente o Estado do Ceará conta com sete eixos de integração de bacias implantados pelo Progerirh, assim constituídas:

1. Alto Jaguaribe - Salgado: túnel que transporta do açude Orós ao açude Lima Campos, com vazão máxima de $5 \mathrm{~m}^{3} / \mathrm{s}$, atendendo ao Perímetro Irrigado Lima Campos.

2. Baixo Jaguaribe - Bacias Metropolitanas (Canal do Trabalhador): canal que transpõe vazão máxima de $6 \mathrm{~m}^{3} / \mathrm{s}$, contribuindo para o fornecimento hídrico da RMF.

3. Médio Jaguaribe - Banabuiú - Bacias Metropolitanas: em construção, transportará águas do açude Castanhão (Pe. Cícero, à Região Metropolitana de Fortaleza e ainda aumentará a oferta hídrica ao Perímetro Irrigado Tabuleiro de Russas, com vazão máxima de $22 \mathrm{~m}^{3} / \mathrm{s}$. 


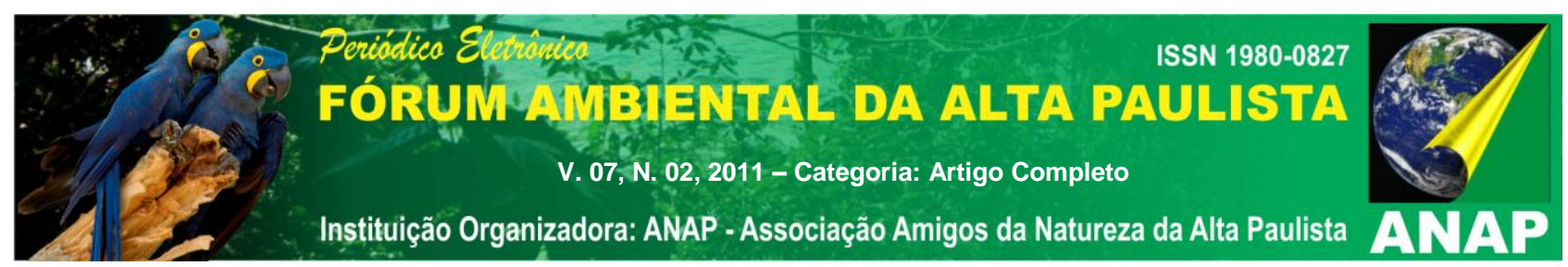

4. Bacias Metropolitanas (Sítios Novos - Pecém): transporta águas do açude Sítios Novos à região portuária do Pecém, com extensão de $24 \mathrm{~km}$ e vazão de $2 \mathrm{~m}^{3} / \mathrm{s}$. Foi concluída em 2001.

5. Bacias Metropolitanas (Rio Pirangi - Lagoa do Uruaú): com vazão de 0,17 $\mathrm{m}^{3} / \mathrm{s}$, coleta água do rio Pirangi, transportando por $12 \mathrm{~km}$ à lagoa do Uruaú em Beberibe.

6. Bacia do Banabuiú (Fogareiro - Pirabibu): transporta uma vazão de $0,11 \mathrm{~m}^{3} / \mathrm{s}$ do açude Fogareiro, em Quixeramobim, ao açude Pirabibu, numa extensão de $10,5 \mathrm{~km}$.

7. Bacia do Alto Jaguaribe (Açude Orós - Feiticeiro): canal adutor que transporta águas da barragem do Orós ao distrito de Feiticeiro, em Jaguaribe.

A respeito da localização desses objetos geográficos, observamos algumas contradições porquanto seu objetivo é acabar, ou pelo menos diminuir, os vazios hídricos do Estado. O fato é que tais objetos são instalados em regiões detentoras de elevada oferta hídrica (isso é percebido quando analisamos o gráfico 2), entre as quais incluem-se a jaguaribana e a metropolitana, em relação a outros pontos do Estado onde tais políticas se dão de maneira bastante pontuais, geralmente no baixo curso dos rios.

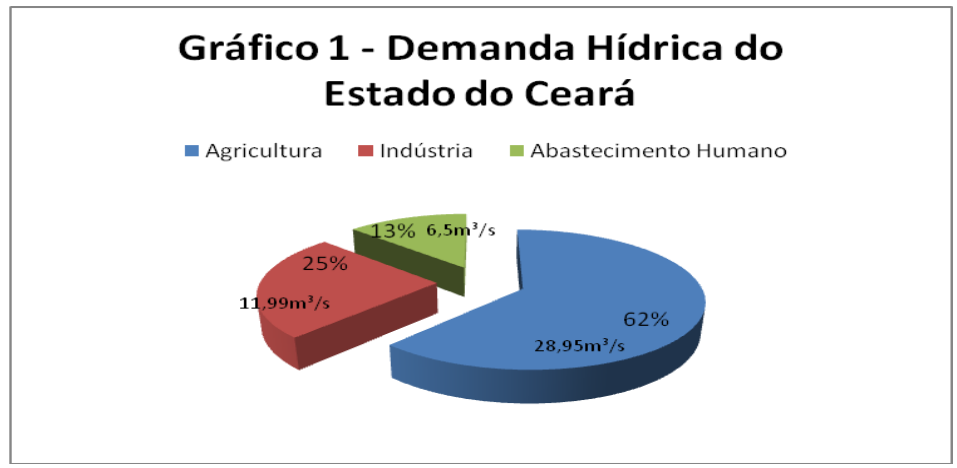

Fonte: Pacto das Águas, 2008.

Elaboração: Cíntia dos Santos Lins

Atualmente o principal fixo em construção, inserido na lógica do Progerirh, é o Canal da Integração. Este, após concluído, abastecerá de água tanto a Região Metropolitana de Fortaleza como o Complexo Industrial e Portuário do Pecém (CIPP), por meio de uma rede de sistemas de engenharias destinadas a transpor os recursos hídricos do açude Castanhão, localizado no Médio Jaguaribe, à RMF. Para tal, contará com recursos públicos, mas sobretudo privados (advindos do Banco Mundial).

4 O NOVO MAPA DAS ÁGUAS DO CEARÁ: A CONSTRUÇÃO DO CANAL DA (DES) INTEGRAÇÃO 


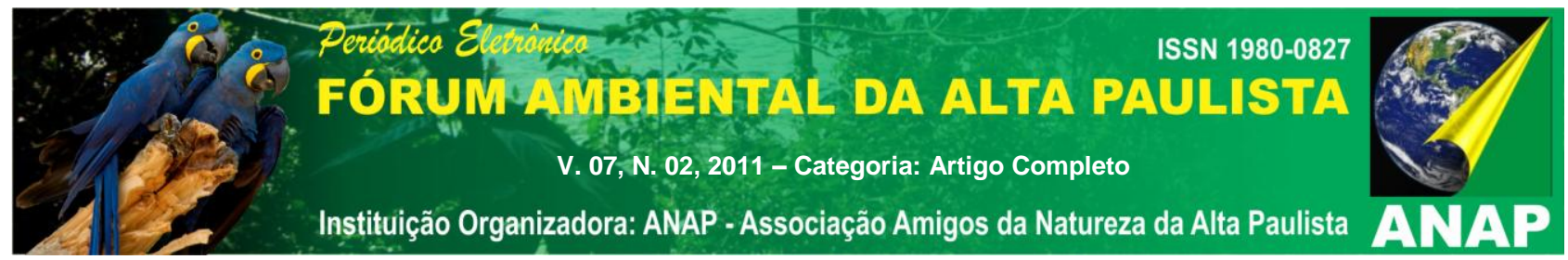

Se fizermos um resgate histórico do processo de gestão dos recursos hídricos do Estado do Ceará, observaremos que a construção de açudes e barragens é um dos métodos mais utilizados. Os estudiosos divergem sobre o assunto. Enquanto Silva e Aguiar Junior consideram essa metodologia como uma das saídas mais eficazes para a resolução dos problemas associados à escassez da água, Rebouças (2004) afirma o contrário. Em seu livro intitulado Uso inteligente da água, conforme o autor evidencia, grande parte dos açudes existentes no semi-árido tem baixa eficiência hidrológica em virtude das altas taxas de evaporação, o que leva à uma diminuição significativa da disponibilidade dos reservatórios, no referente à sua acumulação. Uma das conseqüências dessa alta taxa de evaporação é a redução do nível ótimo (taxa de aproveitamento) desses reservatórios, geralmente em torno de apenas $25 \%$.

Como já expusemos, durante muitos anos os sistemas de ações ${ }^{3}$ relacionados à política de recursos hídricos do Estado do Ceará estiveram voltados, também, à implantação de medidas emergenciais. O Estado atuava somente no período de grandes estiagens via disponibilização de carros-pipa e criação das chamadas "frentes de trabalho" para a intensificação da perfuração de poços com vistas à construção de barragens e estradas. Tais políticas emergenciais são praticadas até hoje no sertão nordestino em virtude de os objetos geográficos implantados para a distribuição de água nas pequenas cidades ainda serem em um número reduzido. São medidas adotadas sem critérios de continuidade e de maneira insustentável, porquanto não são raros os casos de famílias, em períodos de estiagem, que passam quinze dias, ou mais, esperando os carros-pipa chegarem em suas comunidades. Estes sistemas ainda são comuns, como mostram as fotos 16 e 17 sobre pequenas cidades do sertão cearense sendo abastecidas por caminhão-pipa quando a quadra chuvosa se encerra e os reservatórios não secam.

Com a consolidação do sistema de gerenciamento dos recursos hídricos do Ceará, fruto do intenso processo de reestruturação socioespacial, em curso no Estado desde a década de 1980, há uma gama de investimentos em um conjunto de medidas

\footnotetext{
${ }^{3}$ Santos, 1996.
} 


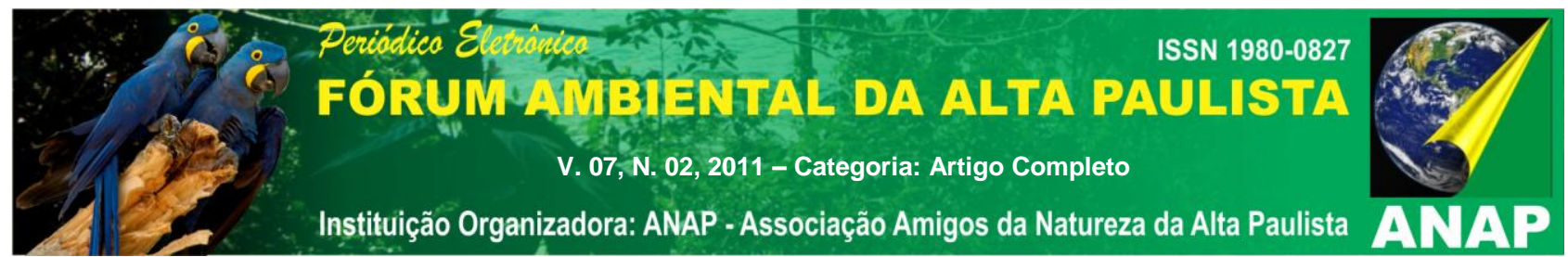

estruturais e não-estruturais ${ }^{4}$ (CAMPOS, 2001) com o intuito de fornecer tal segurança hídrica e suprir as demandas existentes no Estado atualmente.

De modo particular, o Canal da Integração, notadamente com o Progerirh, mesmo sem estar totalmente concluído, é um exemplo claro não só do atual modelo de gestão dos recursos hídricos, mas de como o território cearense se organiza para receber novos investimentos e para ser mantido no rol da produção globalizada.

O Canal da Integração comporta-se como uma verdadeira prótese da natureza ${ }^{5}$. Um rio artificial a ser constituído, após sua conclusão, por um sistema de adução de $255 \mathrm{~km}$ de extensão composto por uma estação de bombeamento, $166 \mathrm{~km}$ de canais, $93 \mathrm{~km}$ de adutoras e $1 \mathrm{~km}$ de túneis divididos em cinco trechos a saber:

$1^{\circ} \rightarrow$ Inicia-se no açude Castanhão e termina no açude Curral Velho;

$2^{\circ} \rightarrow$ Inicia-se no açude Curral Velho e termina na Serra do Félix;

$3^{\circ} \rightarrow$ Inicia-se na Serra do Félix e termina no açude Pacajus;

$4^{\circ} \rightarrow$ Será iniciado no açude Pacajus seguindo até o açude Gavião;

$5^{\circ} \rightarrow$ Será iniciado no açude Gavião e chegará até Fortaleza, seguindo para o Complexo Industrial e Portuário do Pecém e para o Complexo Industrial de Maracanaú.

Em todo o seu percurso, o Canal da Integração cortará os municípios de Alto Santo, Jaguaribara, Morada Nova, Ocara, Cascavel, Pacajus, Horizonte, Itaitinga e Pacatuba. A obra tem como meta a transposição dos recursos hídricos do rio Jaguaribe, a partir do açude Castanhão, para a Região Metropolitana de Fortaleza, interligando as bacias hidrográficas do Vale do Jaguaribe (Banabuiú, baixo e médio curso) e as bacias da RMF (SRH, 2002).

É importante salientar que a área de influência do Canal da Integração é bem mais ampla do que os nove municípios cortados por ele. Segundo observamos, este canal terá forte efeito no desenvolvimento da piscicultura e da carcinicultura, mas sobretudo na atividade industrial (na região metropolitana, principalmente no CIPP,

\footnotetext{
${ }^{4}$ De acordo com Campos (2001), as medidas estruturais são as que estão diretamente ligadas aos sistemas de engenharia, através da construção de objetos artificiais como açudes, barragens, adutoras, canais, entre outros. Já as medidas não-estruturais, são as que atuam na implantação e no gerenciamento das estruturas, através de programas e projetos que auxiliam no controle do uso da água.

${ }^{5}$ Santos, 1988.
} 


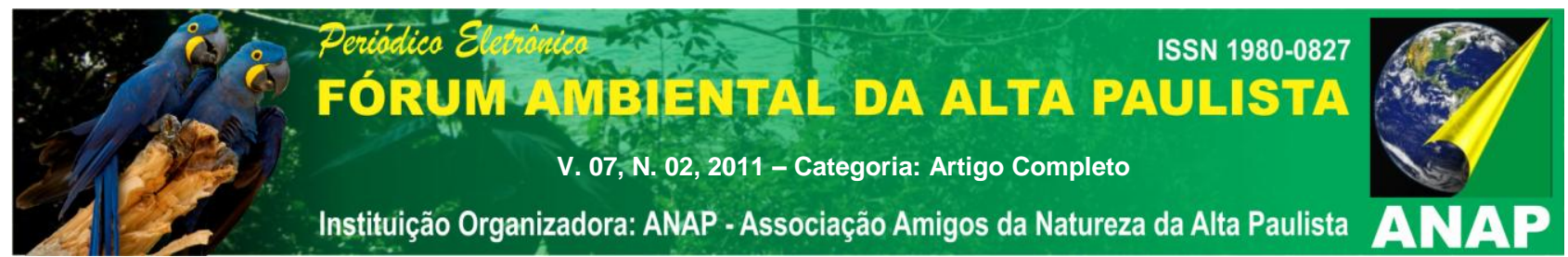

ainda em formação) e na atividade agropecuária (região do Baixo e Médio Jaguaribe e o Banabuiú).

Como mencionamos, o Canal da Integração está sendo construído mediante uma parceria público-privada, entre os governos federal e estadual (junto ao Banco Nacional de Desenvolvimento Econômico e Social - BNDES) e o Banco Mundial. O objetivo, segundo a SRH (2002), é abastecer a Região Metropolitana de Fortaleza, bem como o CIPP e o Complexo Industrial de Maracanaú, por um período de aproximadamente vinte anos, além de proporcionar, nas áreas cortadas por ele, os usos múltiplos da água ${ }^{6}$. Outras instituições, tais como a SRH e o DNOCS, também se manifestam a respeito dos objetivos secundários da implantação do Canal da Integração. Entre estes, podemos citar a necessidade de controlar as cheias ocorridas nos períodos chuvosos na região do Baixo Jaguaribe nos anos de 1974, 1985 e 2004 , que juntas desabrigaram mais de 2 mil habitantes desta região ${ }^{7}$; 0 incremento da piscicultura nos açudes, com ênfase no Castanhão através do Projeto Curupati Peixe e do Projeto Produzir; o beneficiamento da agricultura irrigada nos principais reassentamentos da obra. Esses dois últimos pontos ora citados (projetos de pisciculturas e de agricultura irrigada nos reassentamentos) serão abordados posteriormente por se constituírem alguns dos mais destacados impactos da obra e um dos maiores pontos de tensão do atual modelo de gestão dos recursos hídricos.

Como menciona a $\mathrm{SRH}$, o projeto de construção do canal possibilitará a irrigação de cerca de 40.000 hectares de terras na região do Chapadão do Castanhão e da Chapada do Apodi, além de propiciar o surgimento de um Pólo de Desenvolvimento Hidroagrícola nas áreas de tabuleiro da bacia do rio Jaguaribe. Serão beneficiados cerca de 1.050 hectares de terrenos férteis e favoráveis à agricultura irrigada nas chamadas manchas de solo, bem como na complementação hídrica do projeto do Perímetro Irrigado Tabuleiro de Russas. São áreas distribuídas no Chapadão do Castanhão, do Roldão, de Morada Nova, Ibicuitinga e Ocara.

Seria de uma grandiosidade esplêndida se esses quase 50.000 hectares de terras irrigáveis servissem para fazer ao menos uma pequena porcentagem da tão

\footnotetext{
${ }^{6}$ Uso da água para o abastecimento humano (urbano e rural), agrícola, industrial, para a piscicultura e o setor de serviços.

7 Informações obtidas no site da Secretaria Estadual da Defesa Civil do Ceará. Mais informações: http://www.defesacivil.gov.br/sindec/estados/estado.asp?estado=ce
} 


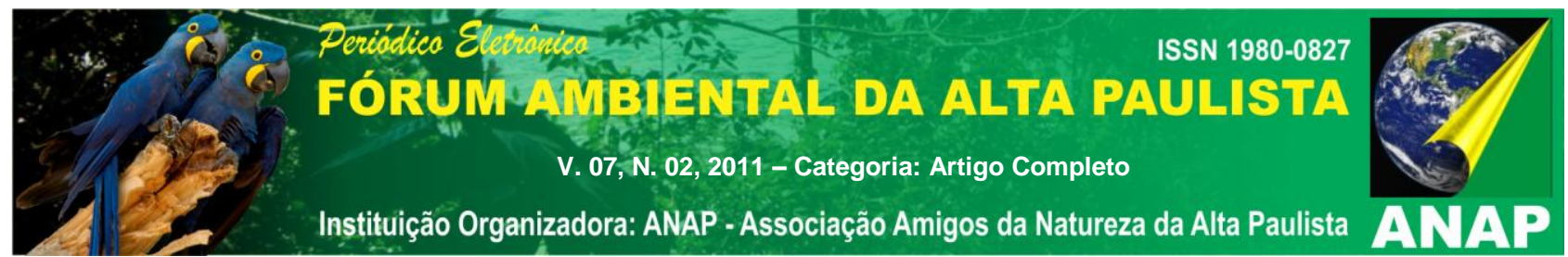

almejada reforma agrária e beneficiasse os pequenos produtores da região e os atingidos pela construção do Canal da Integração. Mas ao fazermos os trabalhos de campo e uma minuciosa análise do projeto da obra, percebemos que os únicos beneficiados com a agricultura irrigada são os grandes empresários agrícolas, em face da elevada capacidade de dialogar com o Estado e, conseqüentemente, disporem de condições de captar recursos e investir na terra e também na água, já que sua captação é cobrada após o término de cada trecho.

As obras do Canal da Integração ainda não estão concluídas, mas segundo estimativas até o ano de 2011 as águas do açude Castanhão deveriam chegar à Região Metropolitana de Fortaleza, com cerca de cinco anos de atraso. O primeiro trecho do canal só foi concluído no final de 2004 em decorrência da falta de recursos financeiros e das fortes chuvas ocorridas no período de janeiro a março do mesmo ano. O segundo e o terceiro trechos estão sendo construídos juntos, e de acordo com a Secretaria de Recursos Hídricos encontram-se, respectivamente, com 97 e 82\% das obras concluídas. Quanto aos dois últimos trechos da obra estão em projeto e não se sabe ainda quando serão iniciados. Contudo, mesmo em fase de conclusão, seus impactos na socioeconomia local já podem ser claramente observados.

\subsection{O primeiro trecho do Canal da (Des)Integração}

O primeiro trecho do Canal da Integração está localizado na bacia hidrográfica do Médio Jaguaribe, inicia-se no açude Castanhão e termina no açude Curral Velho, em Morada Nova. Deste primeiro trecho fazem parte os municípios de Jaguaribara, Jaguaretama, Alto Santo (municípios da bacia hidrográfica do Médio Jaguaribe ${ }^{8}$ ) e Morada Nova (município pertencente à bacia hidrográfica Banabuiú e da microrregião administrativa do Baixo Jaguaribe). Concluída em 2004, tal etapa foi orçada em U\$ 190 milhões de dólares, dos quais $60 \%$ financiadas pelo Banco Mundial e os $40 \%$ restantes pelo governo estadual e federal, junto ao BNDES.

\footnotetext{
${ }^{8}$ São municípios integrantes da região hidrográfica do Médio Jaguaribe: Alto Santo, Deputado Irapuan Pinheiro, Ererê, Iracema, Jaguaretama, Jaguaribara, Jaguaribe, Milhã, Pereriro, Potiretama, São João do Jaguaribe, Solonópoles, Tabuleiro do Norte.
} 


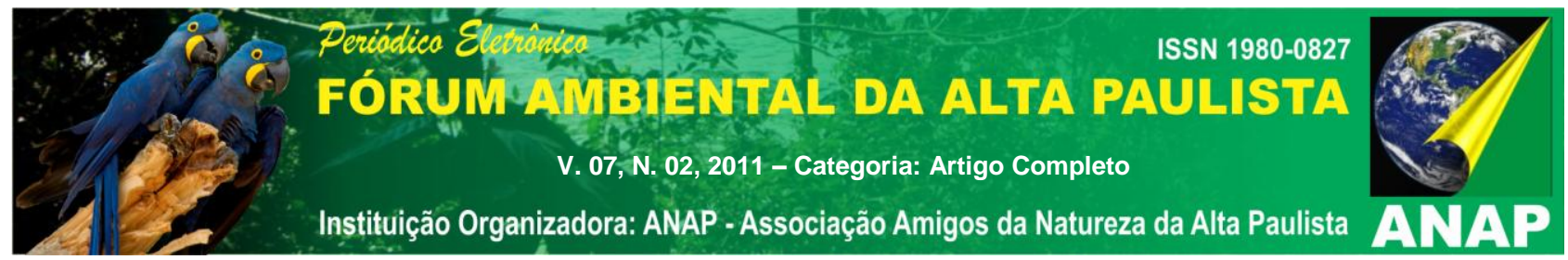

Toda a área foi desapropriada pelo Estado e a população local utilizada como mão-de-obra. Cerca de 1.200 trabalhadores deixaram suas ocupações, geralmente agricultores e pescadores, e se submeteram a outras relações de trabalho, no caso, um trabalho temporário na construção civil. Em atividades de campo e entrevistas com os trabalhadores da obra, segundo afirmaram, a sua quase totalidade foi demitida. Dos 1.200, apenas 12 foram mantidos e passaram a atuar na manutenção da obra. Inúmeros foram os impactos dessa primeira etapa. Alguns estudos realizados por ambientalistas, engenheiros e geógrafos destacaram a inviabilidade da obra por diversos motivos. Entre eles, de acordo com Nascimento (2003, p.30), podemos citar:

A construção de uma área já perenizada pelo Orós, embora fornecendo uma mesma vazão $\left(12 \mathrm{~m}^{3}\right)$; a salinização dos solos do Baixo Jaguaribe, resultando no empobrecimento de importantes terras cultiváveis do Ceará; a evaporação anual equivalente a um açude Banabuiú, dados os 6,8 bilhões de metros cúbicos de água estimados.

Além disso, para a construção do açude, seria necessária a inundação de cerca de dois terços da cidade de Jaguaribara e, por conseqüência, a construção de uma nova cidade. Nesse período, a comunidade jaguaribarense deu início ao movimento "Não ao Castanhão", com mobilizações na tentativa de evitar que a sede de Jaguaribara fosse coberta pelas águas do rio Jaguaribe. Esse movimento foi iniciado porque durante as audiências públicas realizadas pelo DNOCS com o intuito de discutir os impactos da construção do açude, tal instituição se detinha apenas na avaliação dos impactos positivos da obra, sem referência alguma sobre os impactos negativos já levantados por estudiosos da questão.

$\mathrm{Na}$ tentativa de impedir a concretização da obra, a população elaborou um documento, entregue à Secretaria de Meio Ambiente do Estado do Ceará, solicitando que outros objetos geográficos, de menor porte e com menores impactos, fossem construídos ao invés do açude Castanhão. A população cobrava novas alternativas, bem como uma análise detalhada dos impactos sociais, econômicos e culturais de cada uma delas. Nos debates, alguns estudiosos da questão levantaram a possibilidade de serem construídos três açudes de menor porte, mas esta foi descartada pelo governo do Estado do Ceará e, no ano de 1995, foram iniciadas as obras de construção do Castanhão e a cidade de Jaguaribara seria realmente submersa. 


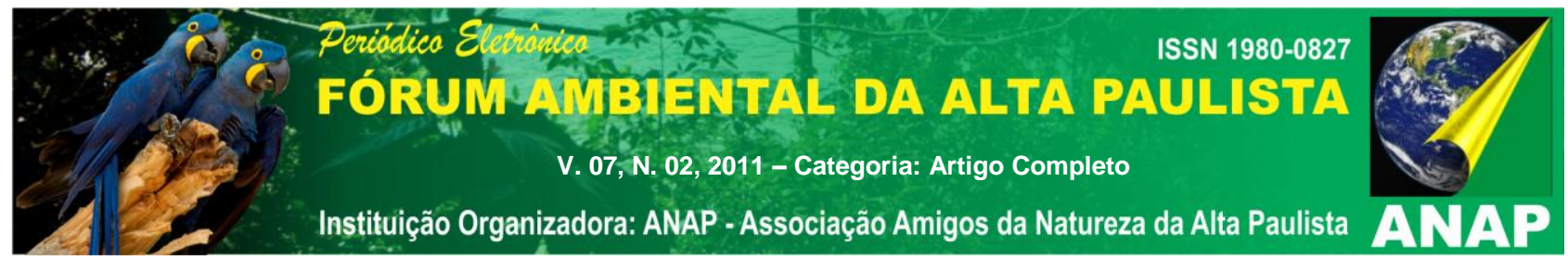

Essa realidade interrompe consideravelmente a história dos jaguaribarenses com seu lugar de vivência, seu espaço coletivo das práticas e motivações sócioeconômicas, políticas e culturais. Essa interrupção foi acompanhada de uma nova construção, não desejada, mas que se tornava real diante da transferência. (NASCIMENTO, 2003, p.31)

A escolha da área foi decidida com base em um plebiscito realizado pelos juízes eleitorais com a população dos municípios de Alto Santo, Jaguaretama e Morada Nova, que cederam parte de seu território para a construção da nova cidade. No mapa 8 e na foto 24 podemos perceber a localização do açude Castanhão, da antiga cidade que foi inundada e a sede da nova cidade.

Inaugurada no ano de 2001, a Nova Jaguaribara está localizada em um planalto, é $100 \%$ saneada, e não possui problemas com águas servidas. De acordo com a $\mathrm{SRH}$, foram realocados o distrito-sede de Jaguaribara, com 3.300 habitantes, o distrito de Poço Cumprido, com 120 habitantes (atualmente é um bairro da nova cidade), e um bairro da cidade de Jaguaretama e Alto Santo, com cerca de 220 moradores. A essas pessoas, foram oferecidos três modelos de residências cujo tamanho baseou-se no das antigas moradias. Embora tenham recebido residências maiores do que as que possuíam na antiga cidade, na opinião dos moradores da região, os únicos beneficiados com a construção da nova cidade foram os que não tinham residência própria. Eram aproximadamente 215 famílias, cerca de 800 moradores (10\% da população total do município), que iriam adquirir suas residências em regime de mutirão. Contudo, esse projeto tornou-se inviável em face da distância entre a nova e a antiga cidade, pois isto acarretaria maiores custos com o transporte constante da população. De acordo com Nascimento (2003), o DNOCS disponibilizou residências de $36 \mathrm{~m}^{2}$ em lotes de $180 \mathrm{~m}^{2}$ a essas famílias e o pagamento das residências deveria ser feito posteriormente mediante prestação de serviços à prefeitura, tanto na nova cidade, quanto nos projetos de reassentamento. Com base nas entrevistas com os moradores, conforme verificamos, a grande maioria deles sentem-se insatisfeitos pelo corte repentino dos laços culturais, porquanto a maior parte da população havia nascido e crescido na antiga cidade. Ademais, a conservação dos limites de vizinhança propostos no projeto não foram respeitados em muitos casos, em virtude da distância entre as residências. 


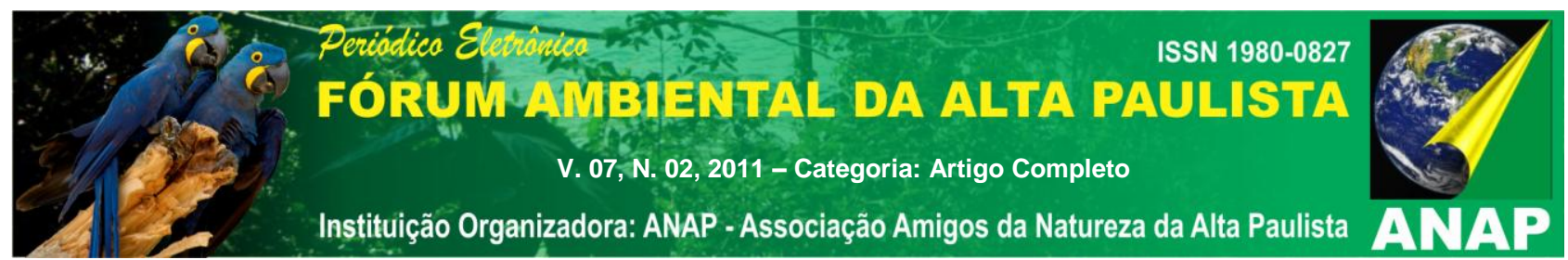

Além de cortar os laços culturais com a antiga cidade, a população também teve de cortar os laços com o rio Jaguaribe. Famílias que viviam basicamente da pesca no rio hoje não podem mais desenvolver tal atividade por conta da distância do mesmo. Tanto os pescadores quanto os trabalhadores rurais adquiriram um lote de terra em um dos projetos de reassentamento, mas grande parte ficou sem produzir porque não foram oferecidos os subsídios necessários à realização da produção (distribuição de sementes, acompanhamento técnico e captação de água). Segundo os moradores não houve uma política de reassentamento adequado na região. Em entrevista ao site comciência, a profa. Marisete Dantas de Aquino, da Universidade Federal do Ceará, que também critica essa falta de um reassentamento adequado, assim se pronunciou:

[...] os donos das terras submersas receberam dinheiro e puderam comprar apartamentos luxuosos de frente para a praia. Já os que trabalhavam nas terras receberam casa e terra. De repente, quem já foi vaqueiro a vida toda passou a ter o lote, além de ser submetida a outra relação de trabalho, a maioria das pessoas não tinha recursos para tocar a terra, como sementes e água, por exemplo. Eles não conseguiram sequer cercar o terreno.

Essa situação se estende até hoje, quase sete anos depois do término das obras do primeiro trecho do Canal da Integração e dez anos após a transferência da população para Nova Jaguaribara. Muitos habitantes da região migraram para outros municípios e perderam o vínculo com sua terra e principalmente com o rio.

A partir de pesquisas bibliográficas, documentais e entrevistas com os representantes do MAB e do DNOCS, principal responsável pela implantação dos reassentamentos, tomamos conhecimento de que além da criação da cidade de Nova Jaguaribara, para a implantação deste primeiro trecho, foram instalados vinte projetos de reassentamento divididos entre os municípios de Alto Santo, Jaguaribara, Jaguaretama e São João do Jaguaribe.

Dos vinte projetos de reassentamento instalados, apenas três são voltados para a agricultura irrigada (Mandacaru, Curupati - Peixe e Irrigação - e Alagamar), os demais, divididos entre os municípios de Alto Santo, Jaguaribara e Jaguaretama, são voltados para a agricultura de sequeiro. Esses três projetos seriam transformados em Projetos-Modelo pelo Governo do Estado do Ceará, entretanto, mesmo quase dez anos após a implantação dos mesmos, nenhum encontra-se em funcionamento, sendo 


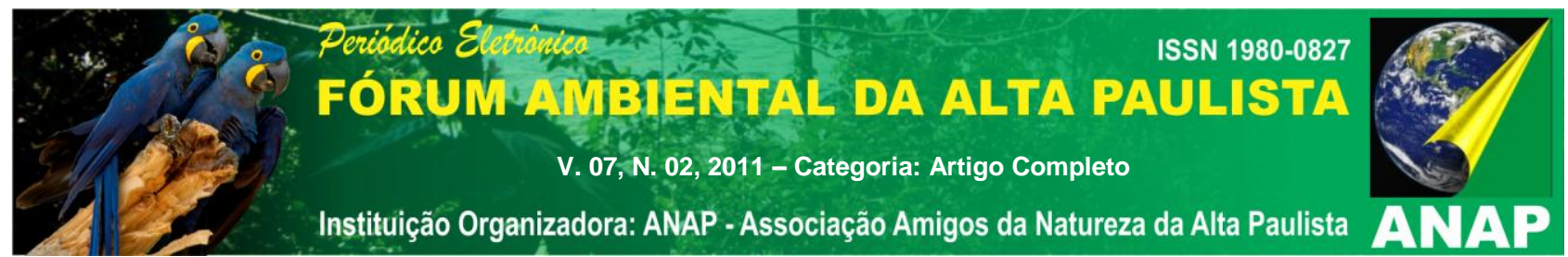

utilizado apenas pela agricultura de sequeiro, já que mesmo estando às margens do Canal da Integração, não possuem acesso à água.

\section{CONSIDERAÇÕES FINAIS}

Consoante observamos na atual política de gerenciamento das águas cearenses há uma grande distância entre o previsto na legislação e o verificado na prática. A gestão deveria ser realizada de maneira descentralizada, participativa e integrada, mas na realidade as decisões estão cada vez mais centralizadas no Estado para atender às necessidades de grandes empresários. A participação da população é dada nos $\mathrm{CBHs}$, porém se resume às decisões a respeito das vazões a serem deliberadas.

Urge adequar o gerenciamento dos recursos hídricos no Estado do Ceará. Tal adequação só será possível quando sua legislação for concentrada em um Estado capaz de suprir a demanda de todas as camadas da sociedade e a partir do momento em que for realizado de baixo para cima. Da forma como ocorre atualmente, privilegia apenas alguns setores da economia e do território, enquanto a maior parte da população permanece às margens, desprovida das mínimas condições de sobrevivência.

\section{REFERÊNCIAS BIBLIOGRÁFICAS}

\section{ASSEMBLÉIA LEGISLATIVA DO ESTADO DO CEARÁ, CONSELHO DE ALTOS} ASSUNTOS ESTRATÉGICOS. Pacto das águas. Fortaleza: Assembléia Legislativa do Estado do Ceará, 2008.

BEZERRA, Hugo Estenio. A gestão da água: o discurso e prática no contexto cearense. In: AMORA, Z.B. (org). Ceará: enfoques geográficos. Fortaleza: Funece, 1999. p. 115143.

CAMPOS, Nilson. Gestão das águas: princípios e práticas. Porto Alegre: $A B R H, 2001$.

CEARÁ. SECRETARIA DE RECURSOS HÍDRICOS DO ESTADO DO CEARÁ. Programa Estadual de Irrigação. Diagnóstico. Vol.1. Fortaleza: SRH, 1998.

Águas do Ceará. Fortaleza, dezembro 2002 (material publicitário). Atlas eletrônico dos recursos hídricos e meteorológicos do Ceará.

Disponível em: http://atlas.srh.ce.gov.br/obras/index.asp Acesso em: 24/4/ 2008. 


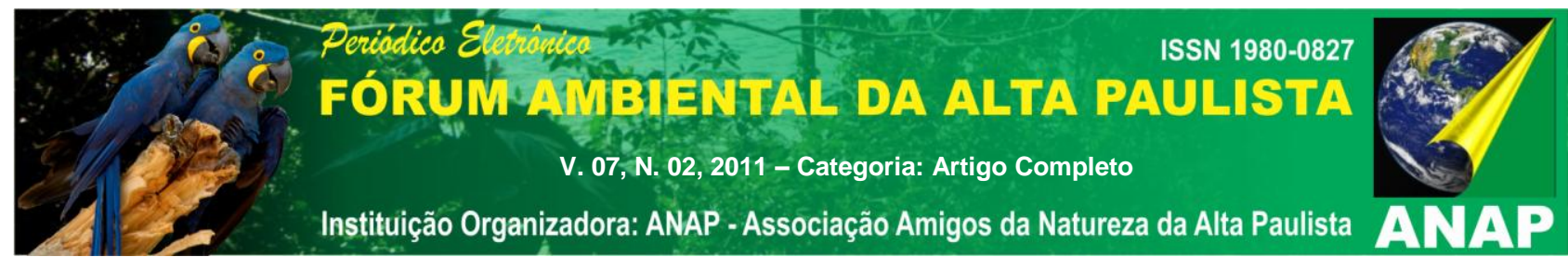

ELIAS, Denise. A atividade agropecuária do Estado do Ceará no contexto da globalização. In: AMORA, Z.B. (org.). Ceará: enfoques geográficos. Fortaleza: Funece, 1999. p.43-72.

ISAC, Francisco. Jaguaribara de Santa Rosa. Fortaleza: IMOPEC, 1999.

O sertão que virou mar. Fortaleza: Premius, 2007.

LANNA, Antônio Eduardo. Modelos de gerenciamento das águas. In: A água em revista. Ano v, n. 8. Belo Horizonte: CPRM, 1997. p 24-33.

LIMA, Luiz Cruz; BOTÃO, Helissandra. O açude público Castanhão (CE) como força reestruturadora do território. In: LIMA, Luiz Cruz (org.) Reestruturação socioespacial: do espaço banal ao espaço da racionalidade técnica. São Paulo: Annablume, 2007.

NASCIMENTO, Maria Anezilany Gomes do. Nem parece o tempo em que vocês jogavam biriba na calçada: o lugar em Nova Jaguaribara. Dissertação de Mestrado. Fortaleza: UECE, 2003.

PETRELLA, Ricardo. A água. O desafio do bem comum. In: NEUTZLING, Inácio (org.). Água: bem público universal. São Leopoldo: Unisinos, 2004.

RODRIGUES. Flávio. Os recursos hídricos e o semi-árido. 2004. (texto debatido no Grupo de discussão realizado durante o seminário em comemoração ao dia do geógrafo na UECE)

SANTOS, MILTON. Por uma geografia nova. Da crítica da geografia a uma geografia crítica. São Paulo: Hucitec, 1980.

Metamorfoses do espaço habitado. 4. ed. São Paulo: Hucitec, 1996.

Por uma outra globalização. Do pensamento único à consciência universal.

Rio de Janeiro/ São Paulo: Record, 2000/ 2003.

SHIVA, Vandana. Guerras por água. São Paulo: Radical Livros, 2006.

SILVEIRA, Edvanir Maia da. Naufrágio de uma cidade: história da resistência da população da cidade de Jaguaribara à sua submersão pela barragem do Castanhão.

Dissertação de Mestrado. Franca: UNESP, 2000. 